\title{
A Study to Assess the Self-Harm Behaviours among Adolescents in a Selected University of Delhi with A View to Develop and Disseminate An Information Booklet on Prevention of Self-Harm Behaviours
}

\author{
Sivasankari. $\mathbf{N}^{1}$, Bindu Shaiju ${ }^{2}$, Jahanara Rahman ${ }^{3}$ \\ ${ }^{1}$ II year M.Sc Nursing, Rufaida College of Nursing, Jamia Hamdard, New Delhi- 440062, India \\ ${ }^{2}$ Assistant Professor, Rufaida College of Nursing, Jamia Hamdard, New Delhi- 440062, India \\ ${ }^{3}$ Tutor, Rufaida College of Nursing, Jamia Hamdard, New Delhi- 440062, India
}

\begin{abstract}
This study aimed to investigate the point prevalence, nature, extent and risk factors of self-harm behaviours among the adolescents aged 17-19 years and to seek the relationship between self-harm behaviours, selected variables and risk factors as well. The objectives also included development of information booklet on prevention of self-harm behaviours. The descriptive survey design included 92 adolescents aged 17-19 years studying in Rufaida College of Nursing, New Delhi, India using Total enumeration sampling technique. Data collected through structured questionnaire was analyzed using descriptive and inferential statistics. The results revealed that the maximum number of adolescents who self-harmed, had moderate severity of self-harm behaviours and most common behaviour indulged was cutting. The area wise analysis of the risk factors revealed that the highest risk factor was socioeconomic status. Information booklet was prepared and disseminated on prevention of self-harm behaviours for adolescents. The study concludes that self-harm behaviours among adolescents have been implicated in the development of low self-esteem and hopelessness and may serve as risk factors for the development of adolescent depression and suicide.
\end{abstract}

Keywords: Self-harm behaviours, Nature, Extent, Risk factors, Information Booklet

\section{Introduction}

World Health Organisation (WHO) defines adolescence as the period of life between 10 to 19 years of age in human growth and development that occurs after childhood and before adulthood. It represents one of the critical transitions in the life span and is characterized by a tremendous pace in growth and change that is second only to that of infancy. Adolescence is a stressful period of physical growth and intellectual attainment at its peak, coupled with set of personality traits, decision regarding future profession, and extreme emotional instability. This is also a period of identity crisis - physical, sexual and spiritual. They will have strong feelings of stress, confusion, fear, and uncertainty, as well as pressure to succeed[1].

Deliberate self-harm (DSH) is a behaviour in which a person commits an act with the purpose of physically harming himself or herself with or without a real intent of suicide. It is also known as self-mutilation, self-abuse, or self-injury. Young adults perform acts of self-harm to overcome and act towards a situation or life crisis that they are facing[1]. Selfinjury is primarily used as a maladaptive coping method among adolescents.

Self-injurious behaviours among adolescents are eliciting increased attention and concern around the world. Research indicates that self-injury tends to first occur during adolescence and is associated with a range of psychiatric disorders, it serves multiple interpersonal and intrapersonal functions and is significantly associated with increased rates of suicide [2].

It's difficult to pinpoint just how widespread the behaviour of self-injury is. It's not tracked by health officials, and prevalence rate of self-harm revealed through research vary widely. There are only few studies conducted in India, to find the prevalence rate of self-harm behaviours. So in order to develop our future generation, extensive research has to be done to find whether self-harm behaviours exists in our adolescents. Adolescents who engage in such activities never understand the graveness and may repeat it for several times. This can even result in loss of life [3].

Until society dispels the myths surrounding this condition through education, sufferers will continue to isolate and keep this mechanism to themselves letting this form of abuse to continue in secret. It is a hidden distress, so adolescents should be driven out from this underworld secretive business and it should also be ensured that adolescents who do so obtain timely help and thus further consequences can be prevented.

Since Self harm behaviours often occurs in private, it is difficult to detect individuals who are self-harming unless they are being treated for related conditions, such as depression or anxiety[2]. Thus, this study is an attempt to give adolescents time for introspection and reflection upon 


\section{International Journal of Science and Research (IJSR) \\ ISSN (Online): 2319-7064}

Index Copernicus Value (2013): 6.14 | Impact Factor (2014): 5.611

themselves and their behaviour patterns which most of us fail to acknowledge.

\section{Literature Survey}

Hawton et.al, conducted a study on Prevalence of deliberate self harm in adolescents and the factors associated with it, in 41 schools. The samples were 6020 pupils aged 15 and 16 years. The study used cross sectional survey design and the samples were assessed using self report Questionnaire. The findings of the study revealed that 398 (6.9\%) participants reported an act of deliberate self harm in the previous year that met study criteria. Only $12.6 \%$ of episodes had resulted in hospitalization. Deliberate self harm was more common in females than it was in males. In females the factors for deliberate self harm included recent self harm by friends and family members, drug misuse, depression, anxiety, impulsivity, and low self esteem. In males the factors were suicidal behaviour in friends and family members, drug use and low self esteem [4].

Morey, Corcoran and Arensman conducted a study to assess the prevalence of self-reported deliberate self harm among adolescents. This study aimed to determine the prevalence of deliberate self harm in adolescents and the methods, motives and help seeking behaviour associated with this behaviour. The sample of the study was 4,583 adolescents aged 15-17 years. A cross-sectional survey was conducted and an anonymous self-report questionnaire was administered in 39 schools. Of the 4,583 adolescents aged 15-17 years, 3,881 $(85 \%)$ adolescents took part in the survey. The findings of the study revealed that $9.1 \%$ of the adolescents reported a lifetime history of DSH. DSH was more common among females $(13.9 \%)$ than males $(4.3 \%)$. Self cutting $(66.0 \%)$ and overdose $(35.2 \%)$ were the most common DSH methods. A minority (15.3\%) of participants accessed medical services after engaging in DSH [5].

Gollust, Eisenberg and Golberstein conducted a study to find out the prevalence and correlates of non suicidal selfinjury in 2010. 2,843 participants were selected from a random sample of 5,021 undergraduate and graduate students . Internet-based survey was used to assess the prevalence of self-injury and potential risk factors including depression, anxiety, eating disorders, suicidal thoughts, and negative health behaviours. The results of the study revealed that $7 \%$ of students reported any form of self-injury over the previous 4 weeks. Factors associated with a significantly higher likelihood of self-injury included cigarette smoking, concurrent depressive and anxiety disorders, and for men, growing up in a family of low socioeconomic status and having symptoms of eating disorders[6].

Hasking, Momeni, Swannell, Chia reviewed the literature to examine the nature, extent and correlates of non-suicidal self injury among 211 young adults. The samples were administered a self-report questionnaire which included the history of Non Suicidal Self Injury(NSSI), emotional regulation, coping strategies, symptoms of psychopathology, and alcohol use. The study concluded that $43.6 \%$ of the young adults reported engaging in NSSI, in which approximately $10 \%$ were engaged in moderate/severe NSSI. Those who reported NSSI reported greater psychopathology, avoidant coping and alcohol use than those who did not selfinjure[7].

Stephen, conducted a study to examine the nature of selfharm behaviours among adolescents in 2011. The study aimed to identify the commonest type of self-harm behaviour. The sample of the study involved 4,700 students from 3 high schools in which 2700 were girls and 2000 were boys. The various methods of self-harm behaviours were used through Online survey method. The findings of the study revealed that teens found to be engaging in self harm behaviour mostly indulged in cutting, which usually involved sharp object such as a razor blades to inflict small cuts on the arms or elsewhere[8].

\section{Materials and Methods}

A quantitative approach with descriptive survey design was used. In this study the conceptual framework was based on, Experiential Avoidance Model developed by Chapman, Gratz et.al., in (2006)[9]. The study was conducted in Rufaida College of Nursing, Jamia Hamdard, New Delhi with 92 samples who were selected through Total Enumeration sampling Technique. Criteria for selection of sample was - Adolescents of age within 17-19 years of age and who were willing and available during data collection period. Administrative permission was taken from Institutional Review Board (I.R.B) of Jamia Hamdard, Delhi, India to conduct the research study. A written informed consent was obtained from each study subject, in addition, coding of the participants names was done which ensured their anonymity.

A structured questionnaire to assess the nature, extent and risk factors of self-harm behaviours was used for data collection. It was divided into 3 sections- Section-I consisted of Demographic data, Section-II consisted of a structured questionnaire to assess the nature and extent of self-harm behaviours. It had 28 Items. Section III was a Structured questionnaire to assess the risk factors of self-harm behaviours among adolescents with a total of 9 Items, In which 3 items were adapted from Kuppuswami, Socio Economic Scale[10]. Reliability of the Structured questionnaire was established by Crohnbach's Alpha and the reliability coefficient was found to be 0.98 . The tool was of sufficient reliability for the purpose of the study. After taking formal administrative permission for conducting the final study, final data was collected. The data collected from the 92 study subjects was planned for analysis using both descriptive and inferential statistics.

\section{Results / Discussion}

The present study revealed that self-harm behaviours was prevalent in age group of 17-19 years which is similar to the findings published by "Australian Bureau of Statistics" in which 6-8 percent of young people aged 15-24 years engage in self-harm in any 12-month period. Lifetime prevalence rates are higher among 17 percent of females and 12 percent of males aged 15-19 years [11]. In the present study, the majority of adolescents who engaged in self-harm behaviours were alone during self-harm behaviours. The present study revealed that majority of the adolescents i.e.

\section{Volume 5 Issue 2, February 2016}




\section{International Journal of Science and Research (IJSR) \\ ISSN (Online): 2319-7064 \\ Index Copernicus Value (2013): 6.14 | Impact Factor (2014): 5.611}

56 percent indulged in cutting themselves and 16 percent adolescents indulged in banging or hitting self and only a small number indulged in other methods. These findings are in agreement with a study conducted by Donald and Greydanus, in which 70 percent of the adolescents indulged in cutting and deliberately overdosing on medication (selfpoisoning)[12]. The present study also identified the area wise analysis of risk factors of self-harm behaviours and it was found out that highest risk factor was in the area of socioeconomic status followed by break-ups in relationship, hopelessness, parental alcoholism, impulsivity, low selfesteem, history of mental illness, academic issues and substance abuse. These findings were similar to a study conducted by Becky Mars, Jon Heron, Catherine Crane, Judi kidger and Glyn Lewis, in which Socioeconomic status, Higher IQ and maternal education were the most common risk factors found among adolescents[13]. The obtained Fisher Exact' $s$ value to establish the relationship between self-harm behaviours, selected variables and risk factors was found to be not statistically significant at 0.05 level of significance.

\section{Conclusion}

The study concludes that the maximum number of adolescents who self harmed, had moderate severity of selfharm behaviours and the commonest type of self-harm behaviour indulged among adolescents was cutting and least indulged behaviour was swallowing dangerous substances. The highest risk factor among adolescents was found to be socioeconomic status. Self harm behaviours among adolescents lead to psychological problems and may serve as risk factors in development of adolescent depression and suicide. Information booklet was prepared and disseminated on prevention of self-harm behaviours for adolescents.

\section{Future Scope}

- A similar study may be replicated on a larger sample covering the entire population of a region or a part of country

- A similar study may be conducted to identify the prevalence of self-harm behaviours among school children

- A comparative study can be conducted to assess the prevalence of self-harm behaviours among boys and girls.

\section{References}

[1] Greydanus DE, Shek DT, "Deliberate self-harm and suicide in adolescents". Keio Journal of Medicine. 2009; 58(3): 144-151

[2] Jennifer J Muehlenkamp, Laurence Claes, "International prevalence of adolescent non-suicidal self-injury and deliberate self-harm", Child Adolescent Psychiatry Mental Health. 2012; 6(10). [Pubmed]

[3] Radhakrishnan.R. et.al., "Suicide: An Indian perspective". Indian Journal of Psychiatry. 2015; 54(4): 304-319.

[4] Hawton K, Rodham K, Evans E, Weatherall R., "Deliberate self harm in adolescents: self report survey in schools in England". British Medical Journal. 2002;325:1207-11. [Pubmed]
[5] Morey C, Corcoran P, Arensman E, Perry IJ. "The prevalence of self-reported deliberate self harm in Irish adolescents". BMC Public Health. 2008; 79(8). [Pubmed]

[6] Gollust SE, Eisenberg D, Golberstein E." Prevalence and correlates of self-injury among university students", Journal of American college health.2008; 56(5):491-8. [Pubmed]

[7] Hasking P, Momeni R, Swannell S, Chia S. "The nature and extent of non-suicidal self-injury in a non-clinical sample of young adults", Journal of the International academy for suicide research. 2008; 12(3):208-18.

[8] Stephen L. "Non-suicidal self-injury, youth, and the Internet: What mental health professionals need to know", Child Adolescent Psychiatry Mental health. 2012; 6(13)

[9] http://www.sciencedirect.com/science/article/pii/S0005 796705000525

[10] Kuppuswami socio-economic scale. Indian Journal of Community Medicine. 2005; Vol. 30(4).

[11] http://headspace.org.au/health-professionals/self-harmand-suicidal-behaviours/

[12] http://www.psychiatrictimes.com/child-adolescentpsychiatry/treating-self-harm-children-and-adolescents

[13] Becky M, Jon H, Catherine C, keith H, "Differences in risk factors for self-harm with and without suicidal intent: Findings from the ALSPAC cohort". Journal of Affective Disorders Journal of Affective Disorders. 2014; 168(15): 407-414.

\section{Author Profile}

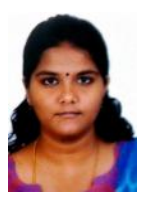

Ms. Sivasankari. $\mathbf{N}$ is pursuing her Masters in Nursing (M.Sc. Psychiatry) from Rufaida College of Nursing, New Delhi and obtained her B.Sc (Hons) Nursing from Govt. College of Nursing, Kozhikode, University of Calicut, Kerala with ( $1^{\text {st }}$ division). She has also obtained her Masters in Business Administration (M.B.A Hospital Management) from Madurai Kamaraj University, Tamil Nadu. She has worked as Staff Nurse in Kozhikode Medical College and has actively participated in various workshops and conferences

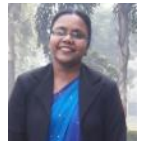

Ms. Bindu Shaiju has obtained her Masters in Nursing (M.Sc. Psychiatry) from R.A.K. College of Nursing, New Delhi. (2004-06) with ( $1^{\text {st }}$ division $)$ and B.Sc. (Hons) in Nursing from All India Institute of Medical Sciences, New Delhi. (1992-1996) ( $1^{\text {st }}$ Rank holder). She has to her credit over 20 yrs of experience in the areas of academic, clinical service in AIIMS, New Delhi and corporate arenas like Max Health Staff in NCLEX-RN training given for Indian nurses aspiring to work in U.S.A as well as ground research experience. Currently she is working as Assistant Professor at Jamia Hamdard (Hamdard University) in the Faculty of Nursing.

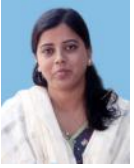

Ms. Jahanara Rahman is a Tutor at Faculty of Nursing, Jamia Hamdard, New Delhi, India. She has done B.Sc. (Hons) Nursing from Govt College of Nursing, West Bengal University of health sciences, West Bengal and M.Sc. Nursing in Child Health Nursing from Asia Heart Foundation College of Nursing, West Bengal University of Health Science. She has 10 years of total experience and has joined Jamia Hamdard in May 2013. She holds membership in professional bodies like Trained Nurses' Association of India, Society of Midwifes in India, Indian Association of Neonatal Nurses and Nursing Research Society of 


\section{International Journal of Science and Research (IJSR) \\ ISSN (Online): 2319-7064}

Index Copernicus Value (2013): 6.14 | Impact Factor (2014): 5.611

India. Research guide for UG and PG students. She has actively participated in various workshops and conferences. Published a research in The Nursing Journal of India. She is an active member in the faculty of nursing. Recognized by IAP as NRP FGM

Regional Trainer. Completed TOT for NRP at Indore, 2014. Involved in teaching nursing Management and paediatrics to graduate and post graduate nursing students. 